\title{
DETERMINAN AKTIVITAS SELF-CARE PADA PASIEN DM TIPE 2 DI RSUD LABUANG BAJI
}

\author{
Determinant Of Self-Care Activities In Type 2 Diabetes \\ Mellitus Patients In Labuang Baji Hospital \\ Natalia Paskawati Adimuntja ${ }^{1}$ \\ ${ }^{1}$ Fakultas Kesehatan Masyarakat, Universitas Cenderawasih \\ (nataliaadimuntja@gmail.com)
}

\begin{abstract}
ABSTRAK
Transisi Epidemiologi ditandai dengan meningkatnya Penyakit tidak menular (Non Communicable Diseases) di masyarakat.Salah satu penyakit tidak menular yang banyak ditemukan yaitu penyakit Diabetes Mellitus (DM) tipe 2.Tujuan penelitian yaitu untuk mengetahui determinan aktivitas self-care diabetes pada pasien DM tipe 2 di Rumah Sakit Umum Daerah (RSUD) Labuang Baji Kota Makassar.Desain penelitian yaitu cross-sectional study.Populasi adalah seluruh pasien DM tipe 2 yang berobat tahun 2016.Penarikan sampel dilakukan dengan teknik probability sampling dengan metode simple random sampling dan jumlah sampel 136 orang. Hasil penelitian menunjukkan, responden dengan aktivitas self-care kurang sebanyak 35 orang $(25,7 \%)$ dan responden dengan aktivitas self-care baik sebanyak 101 orang $(74,3 \%)$. Hasil analisis bivariat (chisquare) menunjukkan bahwa faktor yang signifikan berhubungan dengan aktivitas self-care pasien DM tipe 2 yaitu tingkat pendidikan $(p=0,000)$, lama menderita DM $(p=0,022)$ dan dukungan keluarga $(p=0,000)$. Sedangkan faktor yang tidak signifikan berhubungan yaitu pekerjaan $(p=0,107)$. Hasil analisis regresi logistik menunjukkan bahwa faktor yang berhubungan secara bermakna dengan aktivitas self-care diabetes pada pasien Diabetes Mellitus Tipe 2 yaitu dukungan keluarga $(\mathrm{OR}=42,760 ; 95 \% \mathrm{CI}: 3,797-481,503)$. Kesimpulannya dukungan keluarga merupakan faktor berhubungan secara bermakna dengan aktivitas self-care diabetes.
\end{abstract}

\section{Kata Kunci : Diabetes Mellitus tipe 2, Self-Care}

\section{ABSTRACT}

Epidemiological transitions are characterized by increasing non-communicable diseases in the community. One of the non-communicable diseases that are found is Diabetes Mellitus (DM) type 2 disease. The purpose of this research is to know the determinant of self-care diabetes activity in patients with type 2 diabetes at the Labuang Baji Hospital in Makassar City. The research design is cross-sectional study. The population is all patients with type 2 diabetes DM treatment in 2016. Sampling is done by probability sampling technique with simple random sampling method and the number of sample 136 people. The results showed that respondents with self-care activities were less than 35 people (25.7\%) and respondents with good self-care activities as many as 101 people (74.3\%). The result of bivariate analysis (chi-square) showed that significant factor was correlated with self-care activity of DM type 2 patients with $p$-value $<0,05$ is education $(p=0,000)$, long-suffering diabetes $(p=0,022)$ family support $(p=0,000)$. While the insignificant factor related is occupation $(p=0,107)$. The result of logistic regression analysis showed that the factors significantly correlated with the self-care activity in Diabetes Mellitus Type 2 patients were family support (OR $=42,760 ; 95 \%$ CI : 3,797-481,503). The conclusion of family support is a factor significantly associated with diabetes self-care activities.

Keywords: Type 2 Diabetes Mellitus, Self-Care 


\section{Gorontalo Journal Health and Science Community}

Vol :4, No.1,April 2020

\section{PENDAHULUAN}

Penyakit Tidak Menular (PTM) merupakan masalah kesehatan masyarakat yang menyebabkan kasus kematian utama terhadap 36 juta penduduk dari seluruh kasus kematian di dunia. Data menurut International Diabetes Federation Diabetes Atlas tahun 2017 menunjukkan 425 juta orang menderita diabetes di seluruh dunia. ${ }^{1}$ Jumlah pasien Diabetes Mellitus tipe 2 diperkirakan akan terus meningkat menjadi 592 juta orang pada tahun 2035. ${ }^{2}$ Pasien Diabetes Mellitustipe 2 yang menderita komplikasi, maka akan memberi dampak pada menurunnya kualitas hidup pasien DM tipe $2 .^{3}$

Data prevalensi Diabetes Mellitus sebesar 4\% pada umur 20-44 tahun, umur 45-64 tahun sebesar $16,6 \%$ dan $26,3 \%$ pada orang yang berumur $\geq 65$ tahun. ${ }^{4}$ Prevalensi Diabetes Mellitus di Provinsi Sulawesi Selatan yang didiagnosis dokter sebesar $1,6 \%$, sedangkan yang didiagnosis dokter atau berdasarkan gejala sebesar 3,4\%. Jumlah kasus penyakit DM tahun 2014 di Sulawesi Selatan yaitu sebanyak 27.470 kasus baru dan 66.780 kasus lama dengan 747 kematian. Jumlah kasus Diabetes Mellitus di Kota Makassar pada tahun 2013 yaitu sebanyak 34.396 kasus kemudian meningkat menjadi 61.677 kasus pada tahun 2014 dan menurun pada tahun 2015 yakni sebanyak 36.873 kasus. Data kasus kematian pada tahun 2013 yakni sebanyak 338 kasus kematian kemudian meningkat menjadi 668 kasus kematian pada tahun 2014 dan menurun menjadi 352 kasus kematian pada tahun $2015 .^{5}$

Data rekam medis Rumah Sakit Umum Daerah (RSUD) Labuang Baji menunjukkan jumlah kasus Diabetes MellitusTipe 2 pada tahun 2014 sebanyak 188 kasus Diabetes Mellitus dengan 12 kasus kematian, kemudian meningkat pada tahun 2015 sebanyak 277 kasus dan kembali menurun pada tahun 2016 yaitu sebanyak 231 kasus dengan

21 kasus kematian. ${ }^{6}$ Teori keperawatan mengungkapkan suatu teori terkait self-care yaitu sebagai aktivitas yang dilakukan oleh seseorang dalam memulai dan melakukan suatu tindakan berdasarkan keinginannya dengan tujuan untuk mempertahankan hidup dan kesehatan serta kesejahteraan. Aktivitas self-care yang dapat dilakukan yakni diet, aktivitas/latihan fisik, kontrol glukosa darah, minum obat secara teratur, perawatan kaki dan melakukan perubahan gaya hidup.

Pendidikan dan pekerjaan juga turut mempengaruhi keterampilan self-care pasien Diabetes Mellitus tipe 2.Tingkat pendidikan dapat mempengaruhi self-care pasien, sebagai langkah awal dalam mengendalikan Diabetes Mellitus. ${ }^{7}$ Lama menderita penyakit Diabetes Mellitus tipe 2 turut berpengaruh terhadap self-care diabetes pasien Diabetes Mellitus. Hal tersebut dikarenakan durasi menderita Diabetes Mellitus yang lebih lama akan menambah pemahaman pasien yang adekuat mengenai pentingnya melakukan self-care diabetes, sehingga mendorong mereka untuk mencari 


\section{Gorontalo Journal Health and Science Community}

Vol :4, No.1,April 2020

informasi mengenai perawatan diabetes dan mau secara rutin melakukan aktivitas self-care diabetes. ${ }^{8}$

Faktor yang turut mempengaruhi pasien melakukan aktivitas self-care diabetes yaitu adanya dukungan dari keluarga pasien DM tipe 2.Dukungan keluarga sangat dibutuhkan oleh para penderita DM tipe 2, terutama sebagai pendamping dalam menjalani pengobatan.Dukungan keluarga juga merupakan indikator yang paling kuat memberikan dampak positif terhadap perawatan diri (self-care) penderita DM Tipe 2.Salah satu manajemen dalam perawatan pasien diabetes yaitu keterlibatan dukungan keluarga dalam perawatan.Mematuhi serangkaian tindakan self-care secara rutin yang akan berlangsung seumur hidup pada dasarnya merupakan tantangan yang besar dan bukan hal yang mudah untuk dilakukan. Perasaan jenuh maupun bosan dapat muncul setiap saat yang menyebabkan penderita DM tidak lagi disiplin melakukan tindakan self-care. Sehingga, dukungan keluarga sangat dibutuhkan untuk membantu agar penderita DM Tipe 2 memiliki keyakinan dan kemampuan untuk tetap melakukan tindakan self-care. ${ }^{9}$ Berdasarkan hasil penelitian sebelumnya menunjukkan bahwa ada beberapa faktor yang berkontribusi terhadap self-care pada pasien DMTipe 2. Namun, pada penelitian ini akan berfokus untuk mengetahui faktor yang berhubungan dengan aktivitas self-care diabetes khususnya di Kota Makassar, sehingga peneliti tertarik untuk melakukan penelitian untuk mengetahui faktor yang berhubungan dengan aktivitas self-care diabetes pada pasien DM Tipe 2

di RSUD Labuang Baji Kota Makassar.

\section{BAHAN DAN METODE}

Jenis penelitian yang digunakan rancangan cross-sectional study.Penelitian ini dilaksanakan di RSUD Labuang Baji Kota Makassar pada tanggal 15 April-15 Mei tahun 2017.Populasi dalam penelitian ini adalah populasi kasus yaitu seluruh pasien Diabetes MellitusTipe 2 yang berobat di RSUD Labuang Baji Kota Makassar Tahun 2016. Jumlah sampel sebanyak 136 orang, dengan cara penarikan sampel yakni menggunakan teknik probability sampling dengan metode simple random sampling. Analisis data yang dilakukan adalah analisis univariat, bivariat dan multivariat dengan menggunakan chi-square melalui tabulasi silang dan multiple logistic regression. Aktivitas self-care diabetes berdasarkan aktivitas self-care yang dilakukan dan hasil pengukuran kadar glukosa darah sewaktu pasien yang dilakukan saat penelitian. Untuk pertanyaan lainnya menggunakan panduan kuesioner.Hasil penelitian ini disajikan dalam bentuk tabel dan narasi.

\section{HASIL}

Hasil analisis univariat pada Tabel 1 menunjukkan distribusi responden berdasarkan umur sebagian besar responden yang kurang melakukan aktivitas self-care diabetes yaitu pada kelompok 


\section{Gorontalo Journal Health and Science Community}

umur 50-59 yaitu sebanyak 13 orang (25,0\%). Untuk karakteristik jenis kelamin responden, sebagian besar responden yang kurang melakukan aktivitas self-care diabetes yaitu perempuan yakni sebanyak 29 orang $(30,2 \%)$. Distribusi responden berdasarkan pendidikan, sebagian besar responden dengan tingkat pendidikan tamat SD yang kurang melakukan aktivitas self-care diabetes yaitu sebanyak 12 orang $(48,0 \%)$. Untuk karakteristik pekerjaan, sebagian besar responden yang kurang melakukan aktivitas self-care diabetes yaitu responden yang berstatus tidak bekerja atau Ibu Rumah Tangga (IRT) yaitu sebanyak 18 orang (29,0\%). Pasien DM Tipe 2 yang menderita DM $<5$ tahun dengan aktivitas self-care diabetes kurang yaitu sebanyak 15 orang $(39,5)$, sedangkan responden yang menderita DM selama $\geq 5$ tahun dengan aktivitas self-care diabetes baik yaitu sebanyak 78 orang $(79,6 \%)$. Responden yang kurang melakukan aktivitas self-care diabetes sebagian besar kurang memperoleh dukungan dari keluarga yaitu sebanyak 21 orang $(95,5 \%)$.

Hasil analisis bivariat menggunakan uji statistik chi-square dengan p-value $<0,05$ menunjukkan bahwa faktor yang signifikan berhubungan dengan aktivitas self-care diabetes pada pasien DM Tipe 2 yaitutingkat pendidikan ( $p=$ $0,000)$, lama menderita $\mathrm{DM}(p=0,022)$ dan dukungan keluarga $(p=0,000)$. Sedangkan faktor yang tidak signifikan berhubungan yaitu pekerjaan $(p=0,107)$.
Hasil multivariat pada Tabel 3, variabel yang paling berhubungan secara bermakna dengan aktivitas self-care diabetes pada pasien Diabetes Mellitustipe 2 yaitu dukungan keluarga $(\mathrm{OR}=$ 42,760; 95\% CI : 3,797-481,503). Berdasarkan perhitungan persamaan logistik dan nilai probabilitas dapat disimpulkan bahwa pasien DM tipe 2 yang melakukan aktivitas self-care diabetes dengan memperoleh dukungan dari keluarga memiliki probabilitas berhubungan dengan aktivitas selfcarediabetes yakni sebesar $95 \%$.

\section{PEMBAHASAN}

Tingkat pendidikan yakni jenjang pendidikan formal yang telah ditamatkan oleh responden.Pendidikan baik dan berkualitas yang dimiliki oleh seseorang menjadikan orang tersebut lebih matang terhadap proses perubahan yang terjadi pada dirinya. Hal ini menyebabkan seseorang lebih mudah menerima pengaruh luar yang positif, obyektif dan terbuka terhadap berbagai informasi dan komunikasi mengenai masalah kesehatan yang sedang diderita. ${ }^{10}$ Penelitian ini menemukan pada hasil uji chi-square, variabel tingkat pendidikanmemiliki hubungan dengan aktivitas selfcare diabetes $(p=0.000)$.

Pendidikan adalah salah satu faktor penting yang turut mempengaruhi kemampuan pasien DM Tipe 2 untuk memahami penyakit, perawatan diri (self-care) sampai kepada pengelolaan penyakit DM Tipe 2.Pendidikan tinggi berbanding lurus dengan 


\section{Gorontalo Journal Health and Science Community}

Vol :4, No.1,April 2020

pengetahuan yang cukup pada pasien DM Tipe 2, terutama kecenderungan untuk berusaha melakukan aktivitas perawatan diri (self-care) diabetes yang meliputi mengontrol kadar glukosa darah, mengatur pola makan, melakukan aktivitas fisik dan minum obat secara teratur. Dimana aktivitas self-care diabetes yang telah dilakukannya dapat mencegah terjadinya komplikasi yang dapat mengakibatkan gangguan fungsi fisik, psikologis dan sosial pasien.

Pekerjaan merupakan kegiatan pokok yang dilakukan oleh responden setiap hari untuk memperoleh upah/gaji.Adapun menurut Riskesdas, pekerjaan terbagi atas Tidak bekerja, TNI/POLRI, PNS atau Pegawai, Wiraswasta/Pedagang, Petani/Buruh, dan Lainnya.Faktor sosio-ekonomi yakni salah satunya pekerjaan seseorang.Pekerjaan dalam hal ini terkait juga dengan penghasilan dan tingkat kesibukan seseorang karena harus mengerjakan suatu pekerjaan.Status sosial ekonomi mempengaruhi seseorang melakukan manajemen perawatan diri pasien DM Tipe 2, terutama dalam pencegahan komplikasi. Keterbatasan ekonomi dan tingkat kesibukan yang tinggi dapat menghalangi responden dalam pencarian informasi, terutama informasi terkait manajemen perawatan diri (selfcare) diabetes. ${ }^{11}$ Penelitian ini menemukan variabel pekerjaan tidak memiliki hubungan dengan aktivitas self-care diabetes $(p=0.107)$. Temuan dalam penelitian ini yaitu baik pada responden yang memiliki aktivitas self-care diabetes kurang maupun yang memiliki aktivitas self-care baik, sebagian besar tidak bekerja yakni sebagai ibu rumah tangga (IRT) dan Pensiunan.Berdasarkan hasil uji statistik dengan menggunakan chi-square diperoleh bahwa pekerjaan tidak memiliki hubungan yang signifikan dengan aktivitas self-care diabetes pada pasien DM Tipe 2.Hal ini dapat disimpulkan bahwa baik bekerja maupun tidak bekerja, tidak menentukan kurang atau baiknya aktivitas self-care diabetes pasien DM Tipe 2.

Pekerjaan terkait dengan keadaan ekonomi seseorang dan tingkat kesibukan yang dapat berdampak pada stress yang dialami pasien DM Tipe 2. Untuk itu perlu adanya pengetahuan untuk melakukan manajemen perawatan diri (self-care) yang berasal dari dalam diri pasien DM itu sendiri, sehingga masalah kesehatannya dapat diatasi dan meminimalisir terjadinya komplikasi. Adapun temuan dalam penelitian ini yakni beberapa responden yang bekerja cenderung memiliki aktivitas self-care diabetes yang kurang, dikarenakan tingkat kesibukan kerja sehari-hari yang mengahalangi responden untuk menerapkan pola hidup sehat terutama dalam mengatur pola makan, mengontrol kadar glukosa darah hingga koping stress.

Sedangkan untuk masalah pekerjaan yang terkait dengan keadaan ekonomi, sekarang dapat terbantu dengan adanya pelayanan kesehatan gratis yang diselenggarakan oleh Pemerintah.Sehingga keadaan ekonomi tidak menjadi penghambat pasien DM Tipe 2 dalam melakukan aktivitas self- 


\section{Gorontalo Journal Health and Science Community}

Vol :4, No.1,April 2020

carediabetes. Pelayanan kesehatan gratis yang tersedia bagi keluarga kurang mampu dapat dengan mudah mengakses pelayanan kesehatan, terutama dalam mengontrol kadar glukosa darah, pengobatan sampai konseling gizi. Hal ini menyebabkan bahwa status bekerja dan tidak bekerja seseorang tidak berkontribusi terhadap self-care diabetes pada pasien DM Tipe 2.

Hasil penelitian menunjukkan bahwa ratarata responden menderita DM Tipe 2 yakni selama 9,6 tahun. Dukungan keluarga terhadap aktivitas self-care diabetes di Amerika Serikat juga menemukan rata-rata pasien telah menderita DM Tipe 2 selama 7 tahun atau kurang dari 10 tahun. Penelitian ini menemukan pada hasil uji chi-square, variabel lama menderita DM memiliki hubungan dengan aktivitas self-care diabetes ( $p=0.022$ ).

Pasien DM Tipe 2 yang menderita DM lebih dari 10 tahun menunjukkan perilaku self-care diabetes yang baik dibandingkan pasien DM Tipe 2 yang baru mengalami DM kurang dari 10 tahun. Hal ini dapat disimpulkan bahwa pesien DM Tipe 2 yang telah lama menderita DM telah terbiasa dan dapat mempelajari perilaku self-care diabetes yang dilakukan secara rutin setiap hari selama menjalani perawatan atas penyakit DM yang diderita.Rutinitas perawatan diri ini menyebabkan pasien dapat memahami beberapa aktivitas dari self-care diabetes yang dilakukan yang berguna dalam mempertahankan status kesehatan dan mencegah terjadinya komplikasi. Pemahaman yang adekuat tentang pentingnya self-care diabetes akan terbentuk seiring dengan lamanya pasien menderita penyakit DM, sehingga mendorong para pasien DM Tipe 2 dalam mengakses informasi terkait cara-cara perawatan diri melalui tenaga kesehatan (konseling) maupun melalui media massa. ${ }^{12}$

Lama menderita DM juga terkait dengan terjadinya komplikasi. Adapun beberapa penyakit penyerta (komplikasi) yang banyak diderita responden dalam penelitian ini yaitu antara lain hipertensi, jantung, retinopathy, asam urat, paruparu dan lainnya.Sebagaian besar responden telah lama menderita DM yakni lebih dari 10 tahun, sehingga kejadian komplikasi banyak dialami oleh responden dalam penelitian ini.

Pada umumnya pasien yang belum lama menderita DM Tipe 2 ( $<5$ tahun) masih menganggap beberapa aktivitas self-care sebagai tantangan yang harus dilakukan setiap harinya agar kadar glukosa dalam darah dapat terkontrol. Sedangkan pada pasien yang telah lama menderita DM, sudah menjadikan aktivitas self-care sebagai kebiasaan dan rutinitas yang membentuk pemahaman yang adekuat tentang pentingnya self-care diabetes. Hal demikian menyebabkan lama menderita DM berhubungan dengan aktivitas self-care diabetes pada pasien DM tipe $2 .{ }^{13}$

Dukungan keluarga merupakan salah satu faktor penting yang mendukung dan memfasillitasi pasien dalam melakukan aktivitas self-care diabetes sehari-hari. Keluarga inti merupakan orang yang 


\section{Gorontalo Journal Health and Science Community}

Vol :4, No.1,April 2020

paling terdekat dengan pasien dan mampu mengerti apa yang menjadi kebutuhan dari para pasien DM Tipe 2. Penelitian ini menemukan pada hasil uji chisquare, variabel dukungan keluarga memiliki hubungan dengan aktivitas self-care diabetes ( $p=$ 0.000). Menurut Lawrence Green (1980) dalam Notoatmodjo (2010) bahwa perilaku kesehatan dipengaruhi oleh tiga (3) faktor, yaitu faktor predisposisi seperti pengetahuan, sikap, dan motivasi; faktor pemungkin seperti sarana atau fasilitas kesehatan dan faktor penguat seperti dukungan keluarga, teman dan tenaga kesehatan. Hal tersebut berarti dukungan keluarga turut mempengaruhi perilaku aktivitas self-care diabetes pada pasien DM Tipe 2. Pasien akan kehilangan keyakinan dan motivasi untuk dapat melakukan aktivitas self-care diabetes dan lebih memilih melakukan perawatan diri dengan keterbatasan yang ada pada dirinya sendiri, jika tidak memperoleh dukungan dari keluarga.

Dukungan yang diberikan oleh keluarga kepada pasien DM Tipe 2 dalam penelitian ini meliputi empat dimensi yaitu antara lain dimensi emosional, pengahargaan, instrumental dan informasi. Dukungan keluarga yang meliputi empat dimensi ini berkaitan dengan bagaimana keluarga mengontrol pola konsumsi (diet) pasien, kepatuhan berobat, keteraturan mengontrol kadar glukosa darah dan melakukan olahraga, sehingga mempertahankan status kesehatan tetap baik karena keberhasilan dari aktivitas self-care diabetes yang dilakukan oleh pasien DM Tipe 2. Keluarga yang tinggal satu rumah dengan pasien dapat berperan dalam mendukung perawatan diri pasien melalui menyediakan obat hipoglikemik oral atau obat/suntikan insulin dan alat untuk mengukur kadar glukosa darah digital di rumah. Sehingga glukosa darah pasien pun dapat dikontrol sewaktu-waktu secara rutin. ${ }^{14}$

Penting untuk setiap anggota keluarga menanamkan semangat dan kesadaran dalam diri pasien untuk melakukan manajemen DM melalui aktivitas selfcare diabetes. Anggota keluarga sebaiknya menyediakan waktu agar dapat berkomunikasi dengan pasien terkait apa yang menjadi keluhan dan kebutuhan dari pasien. Komunikasi yang terbangun dengan baik akan memberikan rasa aman dan nyaman kepada pasien, sehingga pasien termotivasi untuk melakukan aktivitas self-care diabetes. Dukungan emosional, penghargaan, instrumental dan informasi dari keluarga yang maksimal akan mencegah timbulnya stress dan perasaan putus asa dalam diri pasien.

Secara fisilogis, dukungan keluarga yang tidak adekuat dapat berpengaruh terhadap meningkatnya kadar kortisol saliva yang dapat memicu naiknya kadar glukosa dalam darah. ${ }^{15}$ Hal tersebut tentu menurunkan status kesehatan. Sehingga dapat disimpulkan bahwa dukungan keluarga turut membantu pasien dalam koping stress.

\section{UCAPAN TERIMA KASIH}

Penulis menghaturkan terima kasih keapda seluruh pihak yang membantu dalam penelitian ini khsusunya Direktur dan seluruh staf RSU.Labuang baji Makassar, serta seluruh tim yang membantu dalam menyelesaikan penelitian ini. 


\section{Gorontalo Journal Health and Science Community}

Vol :4, No.1,April 2020

\section{KESIMPULAN DAN SARAN}

Penelitian ini menyimpulkan variabel tingkat $\operatorname{pendidikan}(p=0.000)$, lama menderita $\operatorname{DM}(p=0.022)$, dan dukungan keluarga $(p=0.000)$ merupakan faktor yang signifikan memiliki hubungan dengan aktivitas self-care diabetes pada pasien DM Tipe 2. Sedangkan faktor yang tidak signifikan berhubungan dengan aktivitas self-care diabetes pada pasien DM Tipe 2yaitu pekerjaan $(p=$ 0,107).Dukungan keluarga merupakan faktor yang berhubungan secara bermakna dengan aktivitas selfcare diabetes pada pasien DM Tipe 2 di RSUD labuang baji Kota Makassar. Oleh karena itu berdasarkan hasil penelitian ini, saran bagi keluarga yang mendampingi pasien dalam mengelola penyakit diabetes yang diderita pasien, sebaiknya memberikan dukungan secara adekuat kepada pasien DM Tipe 2 untuk memantau aktivitas self-care diabetes pasien, salah satunya dengan cara menyediakan alat glukometer di rumah untuk mengukur dan memantau kadar glukosa darah pasien. Bagi petugas hendaknya memberikan edukasi dan konseling kepada pasien dengan jelas, karena dalam penelitian sebagian besar responden merupakan pasien lanjut usia yang sulit mengakses sendiri informasi kesehatan.

\section{DAFTAR PUSTAKA}

1. Bukhsh A, Khan Mehmood T, Nawaz Sarfraz M, Ahmed Sajjad A, et al.Association of diabetes-related self-care activities with glycemic control of patients withtype 2 diabetes in Pakistan. Dove press journal: patient preference and adherence. 2018: 12 2377-2385.

2. Dong $\mathrm{Y}$, Wang $\mathrm{P}$, Dai $\mathrm{Z}$, Liu Ke, et al.Increased self-care activities and glycemic control rate in relation to health education via Wechat among diabetes patients. Medicine journal. 2018: 97:50(e13632).

3. Rahimian Boogar I, Mohajeri-Tehrani MR, Besharat MA, Talepasand S. The effect of sociostructural and collaborative decisionmaking on diabetes self-management. Iranian journal of public health. 2013;42(3):280-92.

4. NCHS. Health, United States, 2017: with special feature on mortality. 2018.

5. Dinkes Provinsi Sulawesi Selatan. Data Penyakit Tidak Menular Tahun 2014. Makassar: Dinas Kesehatan Provinsi Sulawesi Selatan, 2015.

6. Rekam Medik RSUD Labuang Baji. Data Penyakit Diabetes Mellitus Tahun 20142016. Makassar: RSUD Labuang Baji, 2017.

7. Didarloo, A., Shojaeizadeh, D. \& Alizadeh, M. 2016. Impact Of Educational Intervention Based On Interactive Approaches On Beliefs, Behavior, Hemoglobin Alc, And Quality Of Life In Diabetic Women. Int J Prev Med, 7, 38.

8. Kusniawati. 2011. Analisis Faktor Yang Berkontribusi Terhadap Self Care Diabetes Pada Klien Diabetes Melitus Tipe 2 Di Rumah Sakit Umum Tangerang. Universitas Indonesia.

9. Luthfa, I. 2016. Family Support In Patients 


\section{Gorontalo Journal Health and Science Community}

Vol :4, No.1,April 2020

Of Type 2 Diabetes Mellitus Bangetayu Health Center In Semarang, Rasch Model Analysis. Nurscope, 2, 12-23.

10. Taylor, S. A. 2015. Health Psychology, Los Angeles, Mc-Graw Hill Education.

11. Tol, A., Pourreza, A., Shojaeezadeh, D., Mahmoodi, M. \& Mohebbi, B. 2012. The Assessment Of Relation Between Socioeconomic Status And Number of Complications Among Type 2 Diabetic Patients. Iran J Public Health, 41, 66-72.

12. Mayberry LS, Osborn CY. Family involvement is helpful and harmful to patients' self-care and glycemic control. Patient education and counseling. 2014;97(3):418-25.

13. Sharoni, S. A., Shdaifat, E. A., Majid, H. M. A., Shohor, N., Ahmad, F. \& Zakaria, Z. 2015. Social Support And Self-Care Activities Among The Elderly Patients With Diabetes In Kelantan. Malaysian Family Physician: The Official Journal Of The Academy of Family Physicians of Malaysia, 10, 34.
14. Isworo, A. \& Saryono. 2010. Hubungan Depresi dan Dukungan Keluarga Terhadap Kadar Gula Darah Pada Pasien Diabetes Mellitus Tipe 2 di RSUD Sragen. Jurnal Keperawatan Soedirman, 5.

15. Mani, N., Caiola, E. \& Fortuna, R. J. 2011. The Influence Of Social Networks On Patients Attitudes Toward Type II Diabetes. Journal Of Community Health, 36, 728-732. 


\section{Gorontalo Journal Health and Science Community}

Vol :4, No.1,April 2020

\section{Lampiran :}

Tabel 1. Distribusi Responden Berdasarkan Karakteristik Responden dan variabel penelitian di RSUD Labuang Baji Kota Makassar

\begin{tabular}{|c|c|c|c|c|c|c|}
\hline \multirow{3}{*}{ Karakterikstik } & \multicolumn{4}{|c|}{ Aktivitas self-care diabetes } & \multirow{2}{*}{\multicolumn{2}{|c|}{ Total }} \\
\hline & \multicolumn{2}{|c|}{ Kurang } & \multicolumn{2}{|c|}{ Baik } & & \\
\hline & n (136) & $\%$ & n (136) & $\%$ & n (136) & $\%$ \\
\hline \multicolumn{7}{|l|}{ Umur } \\
\hline & 1 & 33,3 & 2 & 66,7 & 3 & 100 \\
\hline $30-39$ & 6 & 31,6 & 13 & 68,4 & 19 & 100 \\
\hline $40-49$ & 13 & 25,0 & 39 & 75,0 & 52 & 100 \\
\hline $50-59$ & 12 & 27,9 & 31 & 72,1 & 43 & 100 \\
\hline $60-69$ & 3 & 15,8 & 16 & 84,2 & 19 & 100 \\
\hline \multicolumn{7}{|l|}{$\geq 70$} \\
\hline \multicolumn{7}{|l|}{ Jenis Kelamin } \\
\hline & 6 & 15,0 & 34 & 85,0 & 40 & 100 \\
\hline Laki-laki & 29 & 30,2 & 67 & 69,8 & 96 & 100 \\
\hline Perempuan & & & & & & \\
\hline \multicolumn{7}{|l|}{ Pendidikan } \\
\hline & 4 & 80,0 & 1 & 20,0 & 5 & 100 \\
\hline Tidak sekolah & 0 & 0 & 3 & 100 & 3 & 100 \\
\hline Tidak tamat SD & 12 & 48,0 & 13 & 52,0 & 25 & 100 \\
\hline Tamat SD & 9 & 37,5 & 15 & 62,5 & 24 & 100 \\
\hline Tamat SMP & 10 & 19,6 & 41 & 80,4 & 51 & 100 \\
\hline Tamat SMA & 0 & 0 & 28 & 100 & 28 & 100 \\
\hline \multicolumn{7}{|l|}{ Tamat PT } \\
\hline \multicolumn{7}{|l|}{ Pekerjaan } \\
\hline & 18 & 29,0 & 44 & 71,0 & 62 & 100 \\
\hline Tidak bekerja & 2 & 15,4 & 11 & 84,6 & 13 & 100 \\
\hline PNS/Pegawai & 0 & 0 & 0 & 0 & 0 & 0 \\
\hline TNI/POLRI & 11 & 36,7 & 19 & 63,3 & 30 & 100 \\
\hline Wiraswasta/Pedagang & 3 & 75,0 & 1 & 25,0 & 4 & 100 \\
\hline Petani/Buruh & 1 & 3,7 & 26 & 96,3 & 27 & 100 \\
\hline Lainnya & & & & & & \\
\hline Lama Menderita DM & 15 & 39,5 & 23 & 60,5 & 38 & 100 \\
\hline $\begin{array}{l}<5 \text { tahun } \\
\geq 5 \text { tahun }\end{array}$ & 20 & 20,4 & 78 & 79,6 & 98 & 100 \\
\hline Dukungan Keluarga & 21 & 95,5 & 1 & 4,5 & 22 & 100 \\
\hline Tidak mendukung & 14 & 12,3 & 100 & 87,7 & 114 & 100 \\
\hline Mendukung & & & & & & \\
\hline
\end{tabular}

Sumber: Data Primer, 2017 


\section{Gorontalo Journal Health and Science Community}

Vol :4, No.1,April 2020

Tabel 2. Tabulasi Silang Faktor yang Berhubungan dengan Aktivitas Self-Care Diabetes Pada Pasien Diabetes MellitusTipe di RSUD Labuang Baji Kota Makassar

\begin{tabular}{|c|c|c|c|c|c|c|c|}
\hline \multirow{3}{*}{ Variabel Independen } & \multicolumn{4}{|c|}{ Aktivitas Self-care Diabetes } & \multirow{2}{*}{\multicolumn{2}{|c|}{ Total }} & \multirow{3}{*}{$\begin{array}{c}p \\
\text { value }\end{array}$} \\
\hline & \multicolumn{2}{|c|}{ Kurang } & \multicolumn{2}{|c|}{ Baik } & & & \\
\hline & $\begin{array}{c}\text { n } \\
(35)\end{array}$ & $\%$ & n (101) & $\%$ & n (136) & $\%$ & \\
\hline \multicolumn{7}{|l|}{ Tingkat Pendidikan } & \multirow{3}{*}{$0,000 *$} \\
\hline Pendidikan rendah & 25 & 43,9 & 32 & 56,1 & 57 & 100 & \\
\hline Pendidikan tinggi & 10 & 12,7 & 69 & 87,3 & 79 & 100 & \\
\hline \multicolumn{8}{|l|}{ Pekerjaan } \\
\hline Bekerja & 16 & 34,0 & 31 & 66,0 & 47 & 100 & \multirow[t]{2}{*}{0,107} \\
\hline Tidak bekerja & 19 & 21,3 & 70 & 78,7 & 89 & 100 & \\
\hline \multicolumn{8}{|l|}{ Lama Menderita DM } \\
\hline$<5$ tahun & 15 & 39,5 & 23 & 60,5 & 38 & 100 & \multirow[t]{2}{*}{$0,022 *$} \\
\hline$\geq 5$ tahun & 20 & 20,4 & 78 & 79,6 & 98 & 100 & \\
\hline \multicolumn{8}{|l|}{ Dukungan Keluarga } \\
\hline Tidak mendukung & 21 & 95,5 & 1 & 4,5 & 22 & 100 & \multirow[t]{2}{*}{$0,000 *$} \\
\hline Mendukung & 14 & 12,3 & 100 & 87,7 & 114 & 100 & \\
\hline
\end{tabular}

Sumber: Data Primer, 2017

Tabel 3. Hasil Analisis Multivariat Faktor yang Berhubungan dengan Aktivitas Self-Care Diabetes Pada Pasien Diabetes MellitusTipedi RSUD Labuang Baji Kota Makassar

\begin{tabular}{|c|c|c|c|c|c|c|}
\hline \multirow{2}{*}{ Step $3^{a}$} & \multirow{2}{*}{ B } & \multirow{2}{*}{ Wald } & \multirow{2}{*}{ Sig. } & \multirow{2}{*}{ OR } & \multicolumn{2}{|c|}{ CI $95 \%$} \\
\hline & & & & & LL & $\mathbf{U L}$ \\
\hline $\begin{array}{l}\text { Dukungan } \\
\text { keluarga }\end{array}$ & 4.561 & 17.227 & .000 & 95.716 & 11.105 & 825.003 \\
\hline
\end{tabular}

Sumber: Data Primer, 2017 